\title{
Auditoria da gestão da inovação no setor bancário: 0 caso do BANESE
}

\begin{abstract}
RESUMO
A gestão da inovação tem assumido papel importante no contexto empresarial atual como forma de obtenção de lucros, eficiência nos processos e flexibilidade estrutural, aspectos importantes para a competitividade e consolidação da organização no mercado. A intenção deste estudo teóricoempírico é analisar o processo de gestão da inovação nas instituições bancárias, tomando-se para estudo o Banco do Estado de Sergipe (Banese) e utilizando-se como ferramenta de análise uma auditoria interna da inovação, consoante modelo proposto por Tidd, Bessant e Pavitt (2008), que se baseia em cinco dimensões: estratégia, processos, organização inovadora, relacionamentos e aprendizagem, sendo o resultado apresentado sob a forma de gráfico radar. Após aplicação de questionários aos gestores dos departamentos do Banese envolvidos com inovação, foram analisadas as respostas, por meio das dimensões do modelo, atribuídos conceitos e identificadas fragilidades, que implicaram sugestões de melhoria, importante contribuição desta pesquisa. Como resultado, verificou-se a carência na disseminação da cultura da inovação com foco no cliente e na competitividade, necessidade de convergência das ações de inovação com o plano estratégico da empresa e de mensuração dos resultados dos projetos inovadores, que devem ser priorizados, com interação entre as unidades departamentais e com os agentes externos de fomento à inovação.
\end{abstract}

Palavras-chave: Inovação. Gestão. Auditoria.

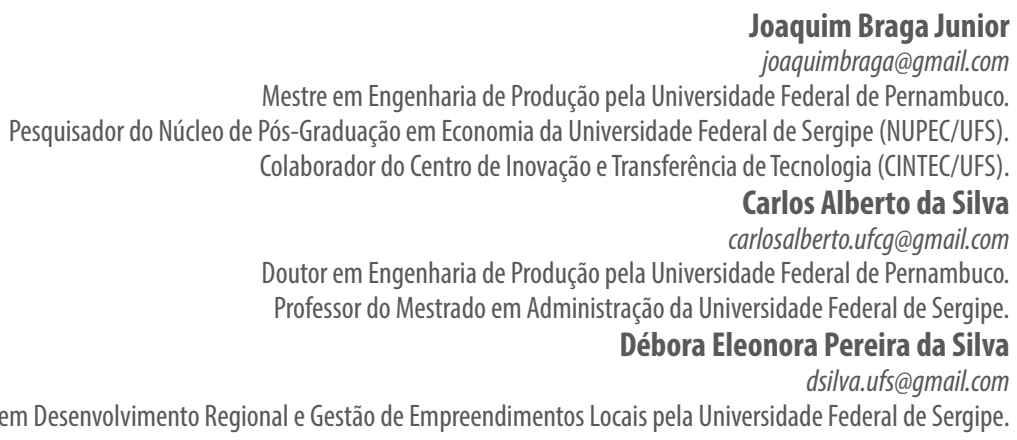

Doutora em Desenvolvimento Regional e Gestão de Empreendimentos Locais pela Universidade Federal de Sergipe. 


\section{INTRODUÇÃO}

O atual ambiente econômico requer, além de capacidade de adaptação e flexibilidade por parte dos entes envolvidos, a aquisição de diferenciais que incorram em vantagens de negócio, de forma a auferir ganho de escala e produtividade, eficiência nos processos e lucros extraordinários. Nesse contexto, a capacidade de inovar assume papel importante, pois enseja vantagens que, se sustentadas, implicam longevidade mercadológica. De modo que a "inovação tem ocupado posição de destaque na academia, principalmente nos últimos anos, em virtude do dinamismo tecnológico e econômico cada vez maior" (LIMA et al., 2007, p. 01).

Contudo, inovar corresponde a um fenômeno complexo e que é disposto sob um enfoque sistêmico. Nota-se, dessa forma, a relevância das práticas de gestão da inovação, como forma de otimizar o referido processo, em todos os seus meandros, além de promover a sustentabilidade das vantagens ocasionadas pela atividade inovadora.

Uma forma de contribuir com as práticas de gestão organizacional e de manter as vantagens ora tratadas é realizar uma auditoria interna, cujo objetivo é demonstrar as fragilidades dos processos empresariais, propondo ações corretivas que mitigam dos riscos inerentes às atividades em lide (TIDD; BESSANT; PAVITT, 2008).

Este estudo propõe, portanto, uma auditoria da gestão da inovação no setor bancário, com aplicação no Banco do Estado de Sergipe S. A. (Banese). A auditoria foi aplicada consoante modelo de auditoria de gestão da inovação proposto por Tidd, Bessant e Pavitt (2008), com base em cinco dimensões - estratégia, processos, organização inovadora, relacionamentos e aprendizagem -, sendo o resultado demonstrado por meio de gráfico em forma de radar.

Como apontam Cernev, Jayo e Diniz (2009), a inovação no sistema bancário é responsável por uma série de modificações e aquisições que permitiram que o setor evoluísse, conhecidas como ondas de inovação, como a automatização dos processos de back-office, a criação de agências eletrônicas, a disseminação dos caixas eletrônicos e o internet banking. Segundo Cernev, Jayo e Diniz (2009, p. 06), a quinta onda de inovação no setor bancário está situada no "desenvolvimento de correspondentes e uso de celulares como canais bancários", o que exige um olhar mais atento por parte dos bancos no que se refere a como lidar com a dinâmica da inovação no setor.

Considerando a inovação um aspecto intrínseco para a competitividade do setor bancário, este estudo, de forma mais específica, buscou avaliar como um banco gerencia suas inovações, averiguar as virtudes e os pontos críticos do processo de gestão da inovação; aferir como a realização de uma auditoria pode contribuir para a gestão da inovação; e recomendar melhorias ao gerenciamento da inovação no Banese.

Para tanto, este texto está dividido em cinco sessões, a contar com esta introdução, sendo elas: (2) referencial teórico, com os principais conceitos relacionados à inovação e ao modelo de auditoria da inovação a ser utilizado; (3) procedimentos metodológicos, com o detalhamento da abordagem de pesquisa escolhida; (4) apresentação e discussão dos resultados; e (5) considerações finais.

\section{REFERENCIAL TEÓRICO}

Nessa seção serão apresentados alguns conceitos relacionados ao conceito de inovação, tipos de inovação, inovação no setor bancário e as especificidades do modelo de Tidd, Bessant e Pavitt (2008), o qual foi adotado como modelo teórico básico para a auditoria da inovação proposta na pesquisa.

\subsection{O que é inovação?}

No estudo da teoria econômica, o termo inovação assume conceitos variados, embora todos relacionados à quebra de paradigmas. Em busca de um melhor entendimento desses conceitos, 0 Quadro 1 apresenta as definições de inovação de alguns autores. 
Quadro 1 - Conceito de inovação

\begin{tabular}{|c|l|}
\hline Schumpeter (1982) & $\begin{array}{l}\text { É o principal elemento da evolução do capitalismo, sob a forma de introdução de } \\
\text { novos bens, técnicas de produção, surgimento de novos mercados, além de fontes } \\
\text { de oferta de matérias-primas e composições industriais. }\end{array}$ \\
\hline Drucker (1985) & $\begin{array}{l}\text { É o instrumento específico dos empreendedores, por meio do qual exploram a } \\
\text { mudança como uma oportunidade para um novo negócio ou serviço diferente, } \\
\text { capaz de ampliar ou mesmo de criar novos mercados. É uma disciplina; logo, pode } \\
\text { ser aprendida e praticada. }\end{array}$ \\
\hline Luecke (2002) & $\begin{array}{l}\text { Introdução de uma nova atividade, incorporando ou combinando conhecimento } \\
\text { em novos produtos, processos ou serviços. }\end{array}$ \\
\hline Katz (2003) & É a introdução de um artigo novo no mercado. \\
\hline Weisberg (2003) & Consiste numa forma estruturada de pensamento. \\
\hline Bernstein (2003) & $\begin{array}{l}\text { Inovação surge de um problema, em que a adequada definição desse problema } \\
\text { evita desperdício de recursos para a respectiva solução. }\end{array}$ \\
\hline $\begin{array}{c}\text { Sternberg, Pretz e } \\
\text { Kaufmann (2003) }\end{array}$ & $\begin{array}{l}\text { Inovação é uma canalização da criatividade, para gerar ideias e produtos que } \\
\text { outras pessoas possam ou desejem usar. }\end{array}$ \\
\hline Stal (2007, p. 28) & $\begin{array}{l}\text { Inovação é “a introdução, com êxito, no mercado, de produtos, serviços, processos, } \\
\text { métodos e sistemas que não existiam anteriormente ou que contenham alguma } \\
\text { característica nova e diferente do padrão em vigor". }\end{array}$ \\
\hline $\begin{array}{c}\text { Tidd, Bessant e Pavitt } \\
\text { (2008) }\end{array}$ & $\begin{array}{l}\text { Inovação é um processo de melhoria contínua a ser gerenciado e disseminado na } \\
\text { organização. }\end{array}$ \\
\hline Chesbrough (2010) & $\begin{array}{l}\text { Inovar significa criar bases que permitam gerenciar os recursos internos e externos } \\
\text { em prol de novas possibilidades e oportunidades. }\end{array}$ \\
\hline
\end{tabular}

Fonte: Dados da pesquisa (2013)

Com base nas definições apresentadas no Quadro 1, pode-se compreender a inovação como um processo de pensar um bem ou serviço novo, ou mesmo aprimorar os já existentes, de forma estruturada, introduzindo-o no mercado e aproveitando uma oportunidade de negócio. De acordo com Castro (2008), existe uma distinção fundamental acerca dos conceitos de inovação no que diz respeito ao seu foco, são elas: as inovações administrativas (ou organizacionais) e as tecnológicas. Uma inovação administrativa refere-se à estrutura e aos processos organizacionais, enquanto a inovação tecnológica corresponde à introdução de tecnologia no processo produtivo.

Com base nessa classificação, tem-se que a inovação tanto pode ocorrer por meio de aparatos tecnológicos que, em virtude de seu uso e utilidade, ocasionam melhorias ou novos formatos, quanto por meio de novas ou melhores formas de se executar ou elaborar um elemento em específico, que pode ser um produto, processo, serviço, dentre outros.

Um aspecto que deve ficar claro, ao se tratar de inovação, diz respeito à distinção entre inovação e invenção, pois, embora tais termos pareçam sinônimos, a característica fundamental que dissocia a invenção da inovação é a economicidade, de modo que uma invenção somente se transforma numa inovação quando ocorre a ocupação de um lugar no mercado, ou seja, quando esta é comercializada (TETHER, 2003). Para isso, a inovação deve ser difundida na população de usuários em potencial. Tal difusão ocorre a partir do momento em que são identificadas as motivações que originaram a criação do novo produto/serviço/processo, seu desenvolvimento ao longo do tempo e os impactos gerados no mercado envolvido (BERNARDES, 2007).

\subsection{Tipos de inovação}

A inovação pode se apresentar sob diversas formas. De acordo com Tether (2003) e Tidd, Bessant e Pavitt (2008), a inovação pode ser classificada em inovação de produto; de processo; de posição; e de paradigma.

A inovação de produto significa desenvolver e disponibilizar no mercado um bem ou serviço inovador, diferenciado, que atenda a necessidades até então não supridas (TETHER, 2003). A inovação ao nível do produto é o tipo mais comum, muito embora novos produtos nem sempre correspondam a sucessos, pois ser novo pode não ser o suficiente (TIDD; BESSANT; PAVITT, 2008).

A inovação no processo de produção de um bem ou prestação de um serviço também pode gerar benefícios surpreendentes e sustentados. Normalmente inovar um processo implica fazê-lo de forma mais dinâmica, envolvendo menores custos ou mesmo promovendo uma melhor distribuição 
da produção. Há casos em que as inovações do processo produtivo geram novos produtos, ou, ainda, subprodutos que podem ser utilizados como diferencial (TIDD; BESSANT; PAVITT, 2008).

Já a inovação de posição sugere a reutilização de um bem, serviço ou insumo produtivo. É a reaplicação desses em outros nichos de mercado, ou em outras etapas do processo de produção a fim de gerar uma vantagem mercadológica (TIDD; BESSANT; PAVITT, 2008).

Por fim, a inovação de paradigma implica a quebra de modelos já solidificados com o tempo (TETHER, 2003). É a mudança na concepção de um produto ou processo, de forma a atender às novas dinâmicas de mercado. Tidd, Bessant e Pavitt (2008) exemplificam a inovação de paradigma com a quebra do modelo de produção de automóveis fordista, em que os carros passaram de artesanais, feitos sob encomenda para poucos abastados, para a produção em larga escala, mais barata e destinada à massa populacional.

Já o Manual de Oslo classifica as inovações em: de produto; de processo; de marketing, que acontece mediante alterações na concepção do produto, no formato da embalagem, posicionamento do produto no mercado, forma de promoção ou formação de preços; e a organizacional, que ocorre quando a empresa reformula suas práticas de negócio no ambiente interno ou externo da empresa (OECD, 2005).

Por sua vez, a Pesquisa de Inovação Tecnológica (PINTEC), publicada pelo IBGE (2008) com dados de 2005, traz conceitos peculiares, quanto às inovações de produto e processo. Conforme a pesquisa, as inovações de produtos, bens e serviços compreendem produtos novos e aperfeiçoados, sendo os novos considerados produtos cujas características fundamentais, como matéria-prima e componentes, diferem dos até então já produzidos; e os aperfeiçoados são produtos existentes que sofreram aprimoramento de desempenho.

No tocante à inovação de processos, a PINTEC conceitua processo tecnologicamente novo ou substancialmente aprimorado como sendo aquele em que ocorre nova produção tecnológica ou aprimoramento substancial. Já Sundbo e Gallouj (1998) discorrem sobre os tipos de inovações associados ao setor de serviços, dividindo-as em cinco categorias:

1) Inovação de produto: um novo produto é oferecido e sua venda implicará prestações de serviços.

2) Inovação de processo: alteração em um ou mais procedimentos para produzir ou prestar um serviço.

3) Inovação organizacional (também tratada como gerencial): uma nova forma de gerenciamento e organização.

4) Inovação de mercado: alterações no mercado, como por exemplo, a descoberta de um segmento antes inexistente.

5) Inovação ad hoc, adocrática ou contingencial: busca para solução de um problema particular apresentado por um cliente. É a construção interativa de uma solução.

Em complemento, Macedo (2008) sugeriu a sexta categoria: a inovação exclusivamente em serviços. Conforme o autor, na referida categoria estaria contemplado o desenvolvimento de softwares, produtos intangíveis. Outro ponto importante a ser abordado, envolvendo a tipificação da inovação, é como ela se processa no ciclo inovador para o meio industrial e o de serviços. De acordo com Bernardes (2007), para a inovação de bens físicos (indústria), a primeira etapa do ciclo inovador corresponde às inovações de produto, seguidas pelas inovações radicais de processo, e, por último, ocorrem as inovações incrementais de processo; para serviços, na primeira etapa, observamse inovações incrementais de processo, posteriormente ocorrendo inovações radicais do processo e, por fim, procedem-se as inovações de produto.

\subsection{Inovação em Instituições Bancárias}

Os bancos são instituições que, em virtude de sua atividade, dependem da tecnologia para se manterem atuantes. Entretanto, de acordo com Vilhena (2011), da mesma forma que vários outros setores, os bancos apresentam dificuldade em usar a tecnologia da informação para mudar as rotinas e os rumos dos mercados, limitando-se a utilizá-la para prestar serviços mais rápidos ou com maior eficiência operacional.

Segundo o autor, os bancos em particular têm se especializado, ao longo dos anos, em copiar uns aos outros, sem apresentar ao consumidor características que propiciem a estes a escolha sobre quais os melhores serviços oferecidos. Bernardes (2007) corrobora esse pensamento, qualificando a imitação dos bancos como uma estratégia defensiva, em que as instituições preocupam-se em aprender com o erro do pioneiro. 
Em estudo aplicado por Pires e Marcondes (2004) juntamente a gestores de bancos, acerca da relação entre o conhecimento, a inovação e a competência em organizações financeiras, os autores concluem que as instituições financeiras não vêm dando importância à gestão da inovação, como tentativa de dispor de diferencial competitivo perante os concorrentes. As competências da empresa e dos colaboradores não são trabalhadas, limitando-se a copiar os serviços já oferecidos, já que não há proteção sobre a marca dos serviços prestados. Trata-se de prática conservadora, marca do sistema financeiro nacional.

Reforçando esse conservadorismo está a forte regulação a que se submete o sistema financeiro nacional, por meio da atuação do Banco Central do Brasil (BACEN), o que contribui para a diminuição da exposição a riscos pelos bancos. Bernardes (2007) enfatiza que a regulação no setor bancário influencia na difusão de produtos e serviços inovadores, já que muitos deles são criados de medidas regulatórias que cumprem a agenda governamental, como, por exemplo, os créditos específicos para aquisição de bens (móveis e imóveis) e de fomento. O microcrédito, por exemplo, foi instituído com base em leis e decretos.

Além da regulação, outros dois fatores impactam diretamente a inovação no setor bancário: o foco de atuação da instituição e o comportamento dos correntistas Cernev, Jayo e Diniz (2009). Para o primeiro fator, um banco, ao inovar pensando no atacado, carece de mais interação com o cliente (convênio com órgãos e prefeituras) e maior customização do serviço; por conseguinte, se atua no varejo, necessita de mais tecnologia - concessão de empréstimos nos canais de atendimento aos funcionários dos órgãos e prefeituras -, possibilitando maior padronização dos seus processos e operações.

Já no tocante ao comportamento do cliente bancário, as constantes inovações das telecomunicações requerem dos bancos o acompanhamento dessa tecnologia, pois cada vez mais os correntistas fazem uso de telefones celulares modernos e internet, cabendo aos bancos transformarem tais meios de comunicações em canais de atendimento para transações financeiras.

Tais aspectos devem ser bem gerenciados pelas instituições bancárias, uma vez que, como apontam Cernev, Jayo e Diniz (2009), a tendência das inovações no setor bancário é de se tornarem mais complexas e dinâmicas, conforme o mercado avança. Além disso, conforme Tidd (2001), os processos internos de inovação e a estrutura de inovação montada por uma organização são fortemente influenciados por contingências ambientais que geram grande incerteza. Assim, o desempenho de uma organização depende da forma como ela gerencia a inovação.

\subsection{Dimensões do modelo teórico}

Tidd, Bessant e Pavitt (2008) propõem um modelo de auditoria da inovação que serve para verificar o que uma empresa fez de certo ou de errado no que se refere a uma inovação em específico, ou a identificar quais os problemas que impedem que as ações de inovação tragam resultados. O questionário apresenta quarenta questões, avaliadas em escala Likert, de 1 a 7, com 1 sendo "definitivamente falso", 2 "falso", 3 "pouco falso", 4 "mais ou menos", 5 "pouco verdadeiro", 6 "verdadeiro" e 7 "definitivamente verdadeiro", voltadas a cinco dimensões: estratégia, processos, organização inovadora, relacionamento e aprendizagem.

As técnicas de auditoria intentam a análise do processo estudado e a identificação de fragilidades a fim de sugerir melhorias. Tal ferramenta serve para avaliar o desempenho inovador em organizações, com base numa autoavaliação (self-assessment). Sendo a inovação um grande diferencial competitivo, Tidd, Bessant e Pivitt (2008, p. 582) entendem ser

\footnotetext{
improvável que uma organização com uma estratégia de inovação não muito clara, com recursos tecnológicos limitados e sem planos de adquirir mais, com fraca gestão de projeto, com poucos relacionamentos externos e com uma organização rígida e não sustentadora, tenha êxito em inovação.
}

Partindo desse pressuposto, foram dispostas cinco dimensões de análise para a auditoria: estratégia, processos, organização inovadora, relacionamentos e aprendizagem. As dimensões representam áreas importantes ao processo de gestão da inovação. Sobre cada dimensão foram feitos oito questionamentos, num total de quarenta, a serem analisados em forma de escala, que procuraram identificar se na organização a inovação sequer é pensada ou se existe uma dinâmica de ideação e implementação de inovações eficaz. As questões de cada dimensão estão embaralhadas no instrumento de coleta, de modo a evitar respostas enviesadas. De forma prática, na auditoria da gestão da inovação, os questionamentos ora referidos foram propostos aos sujeitos da pesquisa, que 
responderam a cada questão, pontuando os itens de acordo com a escala Likert, de 1 a 7, conforme mencionado.

A melhor situação possível é obtida, portanto, quando a todas as respostas é atribuído conceito "7". A pontuação aferida de cada questão é, assim, tabulada de forma a gerar "ratings" para as dimensões. Com base nesses números representativos das dimensões, que consistem na média aritmética das perguntas de cada dimensão, é formado um diagrama que propicia uma avaliação ponderada acerca da gestão da inovação na instituição analisada.

Após tabulação, as respostas permitem informar à organização como é efetivada a gestão da inovação e como os envolvidos lidam com a temática do processo inovador dentro da empresa. $\mathrm{O}$ Gráfico 1 demonstra como é verificado o resultado da aplicação do modelo de auditoria proposto. Trata-se de um gráfico sob a forma de "radar".

Gráfico 1 - Radar conforme modelo

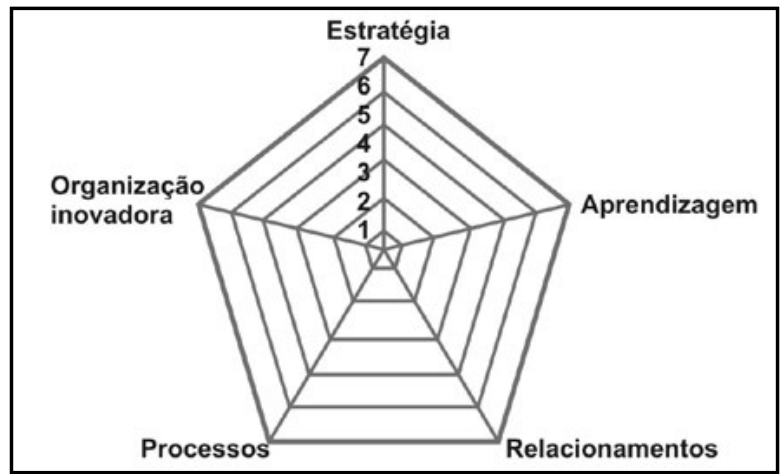

Fonte: Elaborado pelos autores (2013)

De acordo com as respostas dos sujeitos da pesquisa, forma-se uma figura em forma de pentágono que define, dentro da escala proposta, em que nível cada dimensão encontra-se, traçando o panorama de que pontos tratar com mais ênfase e quais são as competências da organização que têm sido mais trabalhadas quando o assunto é inovação.

Formatado o radar, propicia-se a investigação sobre a propriedade com a qual a empresa analisada gerencia seu processo de inovação. Com base nas análises, podem ser identificados fatores de sucesso e de fracasso do processo inovador, além da possibilidade da sugestão de melhorias ao processo como um todo, com base nas dimensões estudadas.

Cada dimensão é explicada nas seções a seguir e referem-se às afirmativas de Tidd, Bessant e Pavitt (2008) acerca do modelo.

\subsubsection{Estratégia}

Consiste num dos principais fatores que contribuem para que uma empresa torne-se ou mantenha-se competitiva no mercado em que atua. No entanto, no campo teórico, seu conceito ainda é bastante discutido, pois a estratégia pode significar desde um curso de ação formulado de maneira precisa, abrangendo não só o posicionamento no ambiente no qual se está inserido, mas também a alma, a personalidade e a razão de existir de uma organização, sendo um conceito muito amplo e diverso. De forma sumarizada, pode-se entender que estratégia é uma ação ou conjunto de ações que devem ser tomadas para atingir objetivos organizacionais definidos, mediante a avaliação do relacionamento e da posição ocupada no segmento produtivo (TIDD; BESSANT; PAVITT, 2008).

\subsubsection{Processos}

Toda empresa é composta por processos. O estudo dos processos tem origem na engenharia industrial, com foco em redesenho, organização e gestão por processos, de modo que não se pode falar em processo sem que a oferta de um produto ou serviço esteja associada. Assim, processo é a atividade ou conjunto delas que se inicia por uma entrada (input) e adiciona-se valor a tal insumo para então se fornecer uma saída (output) a um cliente. Caracteriza-se, dessa forma, um fluxo de trabalho com inputs e outputs claros e que ocorrem dentro de uma sequência de tarefas interdependentes (TIDD; BESSANT; PAVITT, 2008). 


\subsubsection{Organização inovadora}

Uma organização inovadora é aquela que compreende que toda inovação surge a partir da criação de ideias (ideação) que, estimuladas e desenvolvidas, transformam-se em produtos, processos, serviços, tecnologias ou até em empresas (TIDD; BESSANT; PAVITT, 2008).

As inovações podem ser medidas não pela importância científica ou tecnológica que proporcionam, mas pela contribuição que dão ao mercado e aos clientes. Logo, uma empresa é inovadora não por dispor de orçamento para pesquisa, mas por entender que deve avaliar e determinar quanto precisa inovar para, pelo menos, manter-se no mesmo patamar de negócio, relativamente à concorrência. Para tanto, é necessário o abandono de todos os processos arcaicos e infrutíferos que possam vir a acomodar a instituição ou mesmo a causar empecilho ao desenvolvimento das competências da organização, sobretudo no tocante à flexibilidade e adaptabilidade (TIDD; BESSANT; PAVITT, 2008).

\subsubsection{Relacionamento}

Sobre relacionamento organizacional há que se falar em dois ambientes: intraorganizacional e interorganizacional. O primeiro diz respeito à comunicação ocorrida dentro do ambiente da empresa; o segundo, ao contato desta com agentes externos diversos. No campo intraorganizacional, o relacionamento das unidades departamentais é importante na melhoria dos processos, sendo necessária a formatação de um canal de comunicação eficiente (TIDD; BESSANT; PAVITT, 2008).

No que tange ao relacionamento de uma firma com entidades externas quaisquer, a confiança é um fator muito importante e frequentemente mencionado quando são analisadas as relações cooperativas entre firmas, mormente quando estão envolvidos os processos de aprendizagem e inovação. Fala-se isso pelo constante fluxo de informações e recursos envolvidos nas transações de negócio atuais, cuja fidúcia envolvida é basilar para a manutenção dos relacionamentos (TIDD; BESSANT; PAVITT, 2008).

\subsubsection{Aprendizagem}

Aprendizagem organizacional refere-se à capacidade de uma empresa apropriar-se do conhecimento advindo de experiências, de modo a evitar a reincidência de falhas ora cometidas, num processo de melhoria contínua. A aprendizagem organizacional enfatiza o desenvolvimento de estratégias para melhorar continuamente os procedimentos e, por consequência, atingir melhores resultados, devendo ser efetivas a aquisição e a difusão do conhecimento. A aprendizagem é, portanto, uma estratégia inovadora eficiente, pois vislumbra a criação de vantagem competitiva, por meio da formatação de uma memória organizacional (TIDD; BESSANT; PAVITT, 2008).

\section{PROCEDIMENTOS METODOLÓGICOS}

Os procedimentos metodológicos orientam o formato de pesquisa e descrevem as etapas necessárias à sua replicação, além de significarem a visão do pesquisador acerca do tratamento do fenômeno estudado.

Esta pesquisa, quanto à forma de abordagem, pode ser caracterizada como qualitativa, pois que existe uma relação dinâmica entre o mundo real e o sujeito, ou seja, há um vínculo entre o mundo real, objetivo e a subjetividade do sujeito que não pode ser traduzida em números (SAUNDERS; LEWIS; THORNILL, 2012).

Nas pesquisas qualitativas, é frequente que o pesquisador procure entender os fenômenos segundo a perspectiva dos participantes da situação estudada e, a partir daí, situe sua interpretação dos fenômenos estudados. Corroborando o disposto pelo autor, neste trabalho, não foram utilizados métodos estatísticos de análise de dados, sendo as análises realizadas de maneira indutiva, sob enfoque fenomenológico, atribuindo significados aos fenômenos interpretados.

Quanto ao objeto da pesquisa, a técnica é exploratória, pois busca maior familiaridade com o problema da gestão da inovação numa instituição bancária. Conforme Richardson (2008), os principais métodos empregados em estudos exploratórios constituem levantamentos em fontes secundárias, experiências (consultas a especialistas), observação e estudos de caso. "Trata-se da pesquisa que é dedicada a reconstruir teoria, conceitos, idéias, ideologias, polêmicas, tendo em vista, 
em termos imediatos, aprimorar fundamentos teóricos" (DEMO, 2000, p. 20).

No presente estudo, foi realizado inicialmente um levantamento em fontes secundárias, sob a forma de pesquisa bibliográfica. Adicionalmente, foi realizada uma aplicação prática, na forma de um estudo de caso único. A organização escolhida para tal estratégia de pesquisa foi o Banco do Estado de Sergipe S. A. (Banese). Trata-se de um banco público estadual, uma das cinco instituições financeiras estaduais remanescentes no Brasil - Banco do Estado do Espírito Santo (Banestes), Banco do Estado do Rio Grande do Sul (Banrisul), Banco de Brasília (BRB) e Banco do Estado do Pará (Banpará) completam a lista. No estado de Sergipe, atuam quatro bancos públicos, a saber, o Banese, Banco do Brasil (BB), Banco do Nordeste do Brasil (BNB) e Caixa Econômica Federal (CEF).

Segundo Yin (2010), os estudos de casos são utilizados quando há necessidade de se responder questões do tipo "como" e"por que", e quando o escopo da pesquisa é o entendimento de fenômenos contemporâneos complexos. O propósito do estudo de caso foi exploratório, buscando-se uma compreensão maior acerca do processo de gestão da inovação no Banese, por meio da auditoria interna da inovação, sendo utilizado como instrumento de coleta de dados um questionário ou checklist, definido no modelo de auditoria da gestão da inovação, criado em 2008 pelos autores Tidd, Bessant e Pavitt.

Tal instrumento foi levemente adaptado à realidade da empresa-caso, com a inserção do nome da empresa e situações similares à exposta no questionário original. $E$, durante a execução da auditoria, as respostas ao referido checklist foram formatadas com base em questionamentos aos sujeitos envolvidos com as atividades de inovação na organização, a saber, somente os gestores dos dezesseis departamentos (denominados no Banese por "áreas") envolvidos com inovação, seja em crédito, tecnologia, contas correntes, gestão de demandas, canais de relacionamento, serviços bancários, riscos e processos. O Quadro 2 traz um demonstrativo das unidades elencadas.

Quadro 2 - Unidades Departamentais

\begin{tabular}{|c|c|}
\hline Sigla & Nomenclatura \\
\hline ARCOD & Área de Contas e Depósitos \\
\hline ARPAC & Área de Produtos de Crédito \\
\hline ARARC & Área de Análise de Risco de Crédito \\
\hline ARMIC & Área de Microcrédito \\
\hline ACRIM & Área de Crédito Imobiliário \\
\hline ARCRI & Área de Crédito Rural e Industrial \\
\hline SUTEC & Superintendência de Tecnologia \\
\hline ARSET & Área de Serviços de Tecnologia \\
\hline APROJ & Área de Projetos de Sistemas \\
\hline APROC & Área de Processos \\
\hline ARSEC & Área de Segurança da Informação e Continuidade de Negócios \\
\hline ARSER & Área de Serviços e de Retaguarda \\
\hline SUCOR & Superintendência de Controles Internos e Riscos \\
\hline ARGER & Área de Gestão de Riscos \\
\hline ARCAN & Área de Canais de Relacionamento \\
\hline ARGAD & Área de Gestão de Demandas \\
\hline
\end{tabular}

Fonte: Pesquisa de Campo (2013)

Após a aplicação do questionário, os dados foram trabalhados conforme as recomendações do modelo, de modo que foi tirada a média aritmética das perguntas de cada dimensão e formado um radar que define, dentro da escala proposta, em que nível cada dimensão encontra-se, traçando o panorama de que pontos tratar com mais ênfase e quais são as competências da organização que têm sido mais trabalhadas quando o assunto é inovação. 


\section{APRESENTAÇÃO E DISCUSSÃO DOS RESULTADOS}

Nessa seção serão apresentados e discutidos os principais resultados encontrados a partir da aplicação do modelo de auditoria da inovação de Tidd, Bessant e Pavitt (2008).

\subsection{Estratégia}

Ao serem perguntados se os colaboradores do Banese possuem clara ideia de como a inovação é importante para a competitividade organizacional no mercado em que o banco atua, os gestores atribuíram o conceito médio "5,39", que se enquadra como "pouco verdadeiro". Muito embora seja um bom conceito na escala do modelo, constata-se que não é homogênea no quadro funcional a visão de como é vantajoso para a organização inovar para melhor enfrentar os desafios da concorrência.

Quanto a ser a estratégia de inovação do Banese expressa e clara, estando disponível a todo o rol de colaboradores da instituição, para esta indagação, o conceito médio atribuído pelos gestores foi "5,0", ou "pouco verdadeiro", o que pode retratar duas situações: (i) planejamento estratégico, política de lançamento de novos produtos e demais instrumentos condizentes com o tema não devidamente formalizados, disseminados e passíveis de consulta ao corpo funcional da empresa; (ii) inexistência ou insuficiência de instrumentos formais relacionados à inovação.

Ao serem questionados quanto à sociedade conhecer as competências do Banese, onde o banco é atuante, forte, competitivo, o conceito médio extraído foi " 5,50 ", podendo ser entendido como "verdadeiro". O Banese é um banco muito ativo no desenvolvimento de Sergipe, participando em parceria com o governo do estado de projetos e empreendimentos culturais (patrocínios de comemorações festivas municipais e estaduais), comerciais (financiamentos a micro e pequenos empresários, por meio de operações de microcrédito), esportivos (patrocínios de modalidades diversas) e outros. Possui ainda a maior capilaridade (rede de pontos de atendimento) do segmento em Sergipe, estando presente em todo o estado.

Ao serem perguntados se o banco detém planejamento estruturado (baseado em técnicas e ferramentas específicas) no qual são identificadas oportunidades e ameaças, atribuiu-se à questão o conceito médio "5,44", ou "pouco verdadeiro". Dado o conceito e, sabendo-se que são contempladas no planejamento estratégico do Banese as oportunidades e ameaças identificadas, entende-se haver problema de comunicação interna no tocante à disponibilização do planejamento estratégico aos gestores. Ou o documento não é destinado àqueles ou não se dá a devida atenção ao instrumento, de forma a não se aferir a existência dos tópicos tratados na assertiva.

No que diz respeito aos colaboradores possuírem o entendimento de que a empresa desenvolvese apresentando inovações ao mercado de negócios em que está inserida, aferiu-se conceito médio " 5,0 ", ou "pouco verdadeiro". Nos dias de hoje, é muito importante para uma instituição ter arraigada em sua cultura a relevância da inovação para o desenvolvimento organizacional (BERNARDES, 2007).

Quanto à alta administração ser comprometida e patrocinar o processo inovador, obteve-se o conceito médio " 6,0 ", que corresponde a "verdadeiro", denotando que o corpo gerencial envolvido com as ações de inovação no Banese vê com clareza o papel da alta gestão no incentivo à inovação e entende ser satisfatório o patrocínio dado aos projetos inovadores. Tal envolvimento dos administradores, como enfatiza Chesbrough (2010), é condição essencial ao sucesso da inovação.

No que se refere ao banco possuir mecanismos eficientes para examinar inovações dispostas no mercado e avaliar qual o impacto delas no planejamento estratégico da instituição, atribuise conceito médio "4,50", tratado como "mais ou menos". Não se vê confiança, logo, por parte dos gestores, quanto à existência de estrutura interna que avalie novidades mercadológicas e as repercussões delas nos resultados da instituição. O segmento bancário, embora regulado, é bem competitivo, sendo importante a avaliação constante das novidades tecnológicas e de comunicação, para realinhamento de objetivos e estratégias para alcançá-Ios (PIRES; MARCONDES, 2004).

Relativamente a serem os projetos de inovação elaborados de forma clara, conectados com o planejamento estratégico (metas e objetivos) organizacional, obteve-se conceito médio " 5,22 ", ou "pouco verdadeiro". Observa-se, com base na nota apresentada, que nem todos os projetos inovadores são convergentes com o planejamento organizacional, o que no segmento bancário é compreensível, pois a frequente e imperiosa regulação do Banco Central exige a execução de inovações emergenciais que não são logo contempladas nos planos das instituições financeiras.

Para a dimensão estratégica foi obtido um conceito geral de " 5,26 ". 


\subsection{Processos}

Ao serem questionados se a instituição Banese dispõe de processos apropriados que auxiliam o gerenciamento do desenvolvimento de novos produtos/serviços, de maneira eficaz, desde a ideia até o efetivo lançamento, os gestores atribuíram um conceito médio de "4,06", ou "mais ou menos". Verifica-se fragilidade no processo de gerenciamento da inovação, não havendo acompanhamento em grau satisfatório no desenvolvimento de novos serviços bancários, até a chegada desses ao mercado.

No que diz respeito a todos os projetos que envolvem inovação serem realizados de forma eficiente, dentro dos prazos e orçamentos estabelecidos, os sujeitos da pesquisa apontaram, em média, o conceito "3,94", ou "mais ou menos". Fica claro que há problemas na execução dos projetos inovadores, no tocante aos recursos disponibilizados e prioridade de execução de prazo, o que impacta a eficiência do projeto.

Em relação ao Banese deter instrumentos para identificar que todos os colaboradores, e não apenas a área de Marketing, compreendem as necessidades dos clientes, para a questão foi obtido o conceito médio"3,56", ou "mais ou menos", o que permite dizer que não é comum a toda a organização a compreensão do cliente como foco de atuação do Banese, como mencionado na missão do banco "Promover o desenvolvimento de Sergipe fornecendo soluções financeiras, de forma sustentável, gerando valor para seus clientes e acionistas".

Acerca de o Banese deter mecanismo eficaz de gerenciamento de processos (e de suas mudanças), desde a concepção inicial até a implantação das melhorias identificadas, foi aferido o conceito médio " 4,94 ", ou "pouco verdadeiro", de onde se depreende que, como a instituição possui unidade departamental de gerenciamento de demandas e mudanças, esta pode não estar bem difundida na organização. Ainda a respeito de processos, o banco adota em sua estrutura uma Área de Processos (APROC), ligada aos controles internos e gerenciamento de riscos organizacionais, responsável pelo mapeamento e mudanças.

Sobre se o banco sistematicamente busca inovações (em produtos/serviços, processos e outros), os gestores atribuíram conceito médio " 5,17 ", ou "pouco verdadeiro". Na escala conceitual, a nota aferida demonstra constância na procura por serviços inovadores, acompanhando as tendências do segmento bancário. Como exemplo no Banese, pode-se citar a recente implantação de software de gerenciamento integrado para as atividades relativas à contabilidade, gestão de pessoal, manutenção e compras, melhorando os respectivos processos internos.

Quanto ao banco possuir estrutura adequada para garantir a participação de todas as áreas no desenvolvimento das inovações, o conceito médio alcançado foi "4,28", ou "mais ou menos". Não se mostra, portanto, consensual o pensamento dos gestores da inovação do Banese quanto à participação das áreas devidas nos projetos inovadores, o que leva a crer como efetivos os problemas estruturais relacionados ao gerenciamento da inovação. Tal situação mostra-se preocupante, pois, como afirma Chesbrough (2010), a organização inteira deve dar suporte às práticas de inovação.

Ao serem questionados se há uma definição clara das prioridades das inovações na Instituição, os gestores atribuíram o conceito médio " 3,89 ", ou "mais ou menos". A nota evidenciada não permite avaliar como clara tal definição de prioridades, o que causa empecilho à conclusão dos projetos de inovação e pode prejudicar a organização no que tange ao cumprimento do plano estratégico e em termos de atuação no mercado.

Quanto a ser a estrutura do banco flexível e permitir que pequenas inovações desenvolvam-se e sejam implementadas de forma tempestiva, a média obtida dos questionários demonstrou conceito "4,67", ou "pouco verdadeiro". É, entretanto, compreensível a nota observada, tendo em vista que, normalmente, entidades de menor porte tendem a possuir estruturas mais flexíveis. O Banese, muito embora seja um banco pequeno, é uma grande empresa, segundo classificação do Serviço Brasileiro de Apoio às Micro e Pequenas Empresas (SEBRAE) por empregar mais de 99 pessoas (ocupadas).

Consolidando as notas das questões citadas, atribui-se à dimensão processos a nota geral " 4,31 ".

\subsection{Organização inovadora}

Ao serem perguntados se a estrutura organizacional do Banese não reprime o processo de inovação, pelo contrário, favorece-a, os gestores avaliados aplicaram o conceito médio "4,67", ou "pouco verdadeiro". Muito embora o conceito obtido não mostre contundência por parte da empresa quanto ao incentivo das inovações, entende-se que o estímulo inovador é presente. Uma possível justificativa para o conceito é a inexistência de um departamento de gerenciamento de inovações. 
Quanto a haver uma boa interação entre as unidades departamentais da instituição Banese, quando dos projetos de inovação, para esta indagação foi aferido o conceito médio "4,78", ou "pouco verdadeiro". Os projetos de inovação do Banese envolvem as áreas que sofrerão impactos com a implantação da novidade; diante da nota, contudo, entende-se carente o intercâmbio de informação entre as unidades.

Em relação aos colaboradores estarem envolvidos na promoção de ideias de melhorias nos produtos/serviços oferecidos aos clientes, ou mesmo nos processos organizacionais, qualificou-se o conceito médio "4,33", ou "mais ou menos". Inserir os funcionários nos empreendimentos inovadores (TIDD; BESSANT; PAVITT, 2008) agrega valor ao futuro serviço bancário disponibilizado, pois se utilizam a vivência e o constante contato com os clientes, componentes importantes para o sucesso da inovação no mercado. Atualmente, o banco dispõe de um "banco de ideias", no qual se podem sugerir melhorias diversas, previamente avaliadas pela administração da instituição.

Sobre se a estrutura da organização propicia tomada dinâmica de ações, pontuou-se o conceito médio " 5,0 ", ou "pouco verdadeiro". Mais uma vez pontua-se a estrutura do Banese, no que se refere à flexibilidade e dinamismo, agora de forma mais abrangente, não apenas levando em conta ações que vislumbrem inovação. Não se trata de uma estrutura engessada, entretanto, de acordo com a visão dos gestores da inovação, necessita de ajustes, mantendo a empresa dentro de um perfil mais atual de negócio, com ações mais tempestivas.

No que diz respeito a ser a comunicação na organização eficaz e funcionar da mesma forma para todos os níveis da instituição, atribuiu-se o conceito médio "4,11", ou "mais ou menos". A comunicação interna num banco contribui para a melhoria dos processos e, dessa maneira, mostra-se essencial haver um canal eficiente de comunicação. A nota verificada sugere a deficiência da comunicação interna no Banese, realizada hoje por meio de um portal (intranet - rede de computadores interna), seja quanto à ineficiência técnica do canal, seja pela disseminação de sua utilização pelos colaboradores.

No tocante ao Banese estimular, no corpo funcional, a participação no desenvolvimento das inovações, premiando-as, foi obtido o conceito médio " 3,78 ", ou "mais ou menos". Na visão dos gestores, não são satisfatórios e consensuais o estímulo e o reconhecimento pela implementação de inovações no banco. A nota reflete, sem dúvida, uma crítica à estrutura e política de gerenciamento da inovação.

Sobre se o clima organizacional incentiva o desenvolvimento de novas ideias, averiguou-se conceito médio " 3,94 ", ou "mais ou menos". Por não haver clareza na estrutura organizacional sobre inovação, ainda não há clima ou mesmo cultura interna que enfatizem as ideias inovadoras, o que se mostra um aspecto negativo, tendo em vista a cultura ser um dos aspectos cruciais ao gerenciamento eficaz da inovação (STAL, 2007).

Em relação a ser cultural o Banese trabalhar em equipe, formando grupos ou comitês para o desenvolvimento e implementação dos projetos inovadores, obteve-se conceito médio " 5,28 ", ou "pouco verdadeiro". Esta é uma questão que poderia ser provida de conceito mais elevado, pois, como comprova a estrutura organizacional do banco, ele possui atualmente dez comitês de temas diversos.

Para a dimensão organização inovadora, obteve-se nota "4,49".

\subsection{Relacionamento}

Aos serem questionados sobre se o relacionamento do Banese com fornecedores, governo, clientes e demais parceiros é próspero, gerando benefícios para todas as partes envolvidas, os gestores atribuíram conceito médio "5,94", ou "verdadeiro". Compreende-se como notória e satisfatória a parceria do Banese com seus stakeholders. No contexto organizacional contemporâneo, o bom relacionamento e a atuação em redes constituem boas estratégias para obtenção de ganhos de escala e maior competitividade perante as organizações (CHESBROUGH, 2010), e o mesmo se estende aos grandes bancos.

Sobre se o Banese compreende bem as necessidades dos clientes e usuários finais dos produtos/ serviços disponibilizados, aferiu-se o conceito médio "4,78", ou "pouco verdadeiro". A resposta a esta questão possui vínculo e é justificada pela carência de instrumentos que identifiquem se os colaboradores compreendem as necessidades dos clientes a fim de fazer com que a instituição sempre mantenha o foco nos usuários dos serviços.

Em relação ao Banese ter trabalhado em conjunto com universidades e demais centros de pesquisa e conhecimento, atribuiu-se o conceito médio "3,83", ou "mais ou menos". Acredita-se que 
esta questão poderia ter resultado em conceito maior na escala utilizada pelo modelo, já que, como ora dito, o Banese historicamente tem realizado parceria com a Universidade Federal de Sergipe (UFS), no tocante a questões de tecnologia. Vê-se aqui um possível problema de divulgação de projetos de inovação para o corpo funcional.

No que diz respeito ao desenvolvimento de inovações diversas ocorrerem com a interação forte dos clientes, atribuiu-se o conceito médio "3,50", ou "pouco falso". O Banese, atuando como banco de atacado, necessita da interação forte com a clientela, almejando a customização dos serviços prestados para a consequente fidelização do cliente. Enfatiza-se que, atuando como banco varejista, necessita de mais tecnologia, sendo maior o esforço com padronização, em contrapartida.

Sobre se o Banese é parceiro de outras organizações no desenvolvimento de inovações, obtevese o conceito médio "4,44", ou "mais ou menos" para esta colocação, demonstrando que ainda falta à organização envolver o ambiente institucional da inovação quando do desenvolvimento de novos serviços bancários.

Em relação ao banco possuir interesse em formar redes de contato com pessoas, governo e empresas, depreendeu-se o conceito médio "4,89", ou "pouco verdadeiro". Muito embora haja espaço para a participação do Banese no ambiente institucional da inovação, nota-se, com base no grau obtido, que os colaboradores entendem como importante o relacionamento com o citado ambiente, sendo premissa interna a participação em redes de inovação.

No que concerne a haver contato fácil e constante com instituições de ensino (de todos os níveis), para comunicação das necessidades de incremento de competências e habilidades aos colaboradores do Banese, foi extraído o conceito médio " 4,11 ", ou "mais ou menos". Não se mostrou contundente o relacionamento do banco com instituições de ensino em atividades de aprimoramento de capacidades e competências dos funcionários do Banese. A resposta pode ser vista como uma necessidade apontada pelo corpo gerencial da inovação e como um indicador à administração da necessidade de capacitação laboral.

Sobre se, durante a concepção dos projetos que envolvem inovação, os principais beneficiados com as inovações participam de maneira efetiva, referido ponto gerou conceito médio "4,94", ou "pouco verdadeiro". Formados os grupos de trabalho para fomento aos projetos inovadores, carecese dos beneficiários internos da inovação um grande grau de comprometimento e participação, minimizando riscos e a possibilidade de insucesso do projeto.

Para a dimensão relacionamentos, a nota geral obtida foi " 4,56 ".

\subsection{Aprendizagem}

Ao serem questionados se há um forte comprometimento do Banese com a execução de capacitações e desenvolvimento das competências dos colaboradores, os gestores atribuíram a média de "4,28", ou "mais ou menos". Da mesma forma que a resposta obtida para a questão que trata o contato do banco com instituições de ensino para capacitação, nota-se demanda dos gestores da inovação sobre desenvolvimento de competências, sendo um sinal à alta administração.

No questionamento se os projetos de inovação são revisados, após a implementação, a fim de que, no futuro, as falhas identificadas em projetos anteriores sejam evitadas, extraiu-se o conceito médio "4,0", ou "mais ou menos". Averiguou-se um conceito baixo para uma questão tão importante. A revisão de projetos de inovação implantados é condição essencial no processo de melhoria contínua, para que a empresa aprenda com os erros e incremente suas atividades.

Sobre se é cultura do banco revisar as ações realizadas, de forma que se aprenda com o erro, o conceito médio obtido foi "3,78", ou "mais ou menos". Esta afirmação é mais abrangente do que a anterior, não se limitando a discorrer acerca da cultura de aprendizado com os erros apenas para projetos de inovação, mas para a firma integralmente. A ligeira queda de conceito reverbera a necessidade de revisar ações realizadas, revisão que pode ocorrer por meio de um teste de aderência, aferindo-se se o projeto foi devidamente cumprido e se as diretrizes traçadas ajudaram na obtenção de resultados convergentes com o plano estratégico.

No que diz respeito aos produtos/serviços e processos disponibilizados serem periodicamente comparados aos dos concorrentes, foi depreendido o conceito médio "4,67", ou "pouco verdadeiro". No segmento bancário, os serviços oferecidos pelas diversas instituições financeiras são, em muito, similares. Até mesmo os processos são parecidos, por serem também os mesmos fornecedores de sistemas e empresas de consultoria. Dessa forma, não parece ser difícil realizar comparações com a concorrência, num esforço de benchmark que faz parte do processo de melhoria contínua (VILHENA, 2011). 
Corroborando o aspecto anterior, no que concerne ao Banese adotar a prática de fazer contato com outras empresas, com a finalidade de aprender técnicas e boas práticas de inovação, trocando experiências, aferiu-se o conceito médio " 5,44 ", ou "pouco verdadeiro".

No questionamento sobre se é cultura do banco internalizar o conhecimento adquirido (captar e implementar internamente o que se aprende no mercado), os gestores da inovação do Banese atribuíram o conceito médio "4,22", ou "mais ou menos". Não basta participar de benchmark, mas, com base nele, deve-se avaliar a expertise ao qual o banco foi exposto e procurar internalizar esse conhecimento, que deve ser formalizado pela instituição (PIRES; MARCONDES, 2004).

Sobre se é cultura do Banese aprender com outras instituições, obteve-se conceito médio "5,33", ou "pouco verdadeiro". Entende-se como um ponto positivo estar arraigada à cultura do Banese a aprendizagem com outras organizações, sendo tal atividade fundamental para o desenvolvimento da gestão da inovação e do aprimoramento organizacional de uma forma geral.

Sobre se, na identificação das oportunidades de inovação, há critérios que mensuram onde, quando e quanto se pode melhorar, obteve-se o conceito médio " 3,50 ", ou "pouco falso". Na ótica dos gestores avaliados, o banco é carente de critérios e ferramentas que dimensionem e quantifiquem as oportunidades de inovação, o que representa uma fragilidade ao processo de inovação e uma carência do ponto de vista de sua gestão, pois, sem o devido arcabouço teórico e prático, a avaliação de uma possível demanda de inovação não é completa.

O conceito para a dimensão aprendizagem foi de " 4,40 ".

\subsection{Representação Gráfica das Dimensões}

Obtidos os conceitos gerais de cada dimensão, formatou-se um diagrama de radar, por meio do aplicativo Excel, mostrando a condição ideal (todas as dimensões com o maior conceito, ou seja, "7,0") e a condição derivada da auditoria realizada.

Quadro 3 - Valores atribuídos às dimensões do modelo

\begin{tabular}{|c|c|c|}
\hline Dimensão & Auditoria realizada & Condição ideal \\
\hline Estratégia & 5,26 & 7,0 \\
\hline Processos & 4,31 & 7,0 \\
\hline Organização inovadora & 4,49 & 7,0 \\
\hline Relacionamentos & 4,56 & 7,0 \\
\hline Aprendizagem & 4,40 & 7,0 \\
\hline
\end{tabular}

Fonte: Elaborado pelos autores (2013)

Gráfico 2 - Radar da gestão da inovação

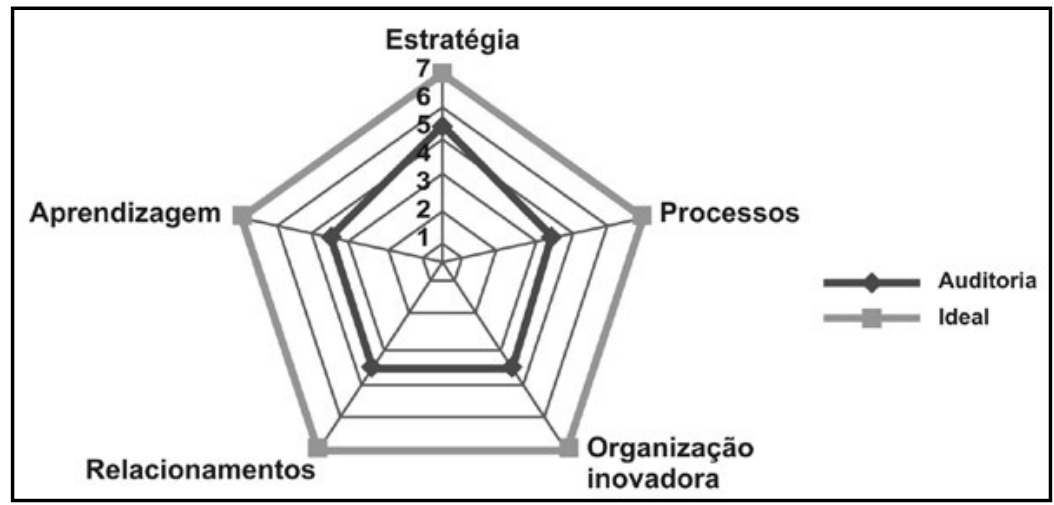

Fonte: Elaborado pelos autores (2013)

O Gráfico 2 permite pontuar as necessidades de melhoria da gestão da inovação no Banese. A estratégia consistiu na dimensão mais desenvolvida, sendo o ponto forte, caracterizando-se que os projetos inovadores intentam o atingimento das metas e dos objetivos organizacionais.

As demais dimensões apresentaram-se num mesmo patamar, inferior ao da estratégia. Mostraram-se, portanto, mais carentes de gestão, sendo necessário maior incentivo à aprendizagem (internalização de conhecimento), melhor relacionamento com o ambiente institucional da inovação, clareza e melhoria contínua dos processos internos e aculturamento dos colaboradores 
quanto à importância da inovação para o desenvolvimento organizacional. Nota-se, com isso, que o resultado obtido é satisfatório e que, embora descolado da caracterização do "mundo ideal", enseja incremento do ponto de vista de gestão. Há uma proporção entre as figuras obtidas (auditoria e ideal), o que aponta uniformidade no grau de desenvolvimento das dimensões.

Aliado a isso, conforme ressaltam Tidd, Bessant e Pivitt (2008), o conhecimento da atual situação da empresa serve como um passo ao estabelecimento de ações corretivas voltadas ao gerenciamento eficaz da inovação, de modo que, no caso do Banese, e de outras instituições financeiras, a auditoria da inovação constitui passo importante dentro desse processo de melhoria contínua e mudança.

\section{CONCLUSÃO}

Esteestudopermitiualgunsindícios daimportância dagestãoda inovação parao desenvolvimento organizacional das empresas, notadamente o setor bancário, cujo conteúdo tecnológico é evidente. A inovação assume então papel estratégico como condição essencial à competitividade e ganhos de escala no atual ambiente globalizado. Constatou-se que a teoria da inovação em muito ainda se atém ao setor industrial, sendo incipiente a análise dos serviços da economia e pequena a quantidade de estudos empíricos que avaliem a inovação no setor bancário, sobretudo no que tange à gestão do processo inovador, sendo esta uma contribuição do presente trabalho.

Constatou-se que o Banese gerencia seu processo inovador, tendo como maior qualidade o vínculo dos projetos com o planejamento estratégico, e sendo identificadas fragilidades acerca da cultura de aprendizagem, relacionamento institucional com os agentes de fomento à inovação, consciência coletiva da importância da inovação para a competitividade e desenvolvimento dos conceitos de mapeamento de processos e melhoria contínua desses.

Tais aspectos não estão em conformidade com as ideias de Cernev, Jayo e Diniz (2009), que apontam a quinta onda de inovação como pautada nos relacionamentos e na importância em se adequar às novas exigências de mercado. As instituições bancárias devem considerar, dentro de suas estratégias de inovação, uma gestão baseada na análise crítica de seu ambiente interno e externo, e na consolidação de um bom relacionamento com seus parceiros, clientes e demais integrantes do mercado.

O lançamento de novos serviços bancários não demonstrou contemplar a preocupação com a gestão e internalização do conhecimento, em virtude do mote da imitação. Relativamente a esse aspecto, embora a imitação possa resultar na adoção rápida de novos procedimentos, essa também faz com que a organização não crie mecanismos que lhe permitam criar novos formatos de negócio, práticas e produtos, o que pode fragilizar sua atuação de mercado.

Nas melhorias propostas, podem ser enfatizadas questões como a disseminação da cultura da inovação com foco no cliente e na competitividade, convergência das ações com o plano estratégico da empresa, melhor estrutura, revisão e mensuração dos resultados dos projetos inovadores, priorização de demandas inovadoras, flexibilidade organizacional, interação entre unidades departamentais e com os agentes de inovação e desenvolvimento das competências dos colaboradores.

Avaliou-se que a gestão da inovação ainda não é vista com a importância devida, mostrando-se ainda carente. Corroboram tal colocação Pires e Marcondes (2004), ao afirmarem que as instituições financeiras não vêm, historicamente, dando a devida importância à gestão da inovação, vislumbrando a tentativa de dispor de diferencial competitivo diante dos concorrentes mercadológicos. As competências da empresa e dos colaboradores não são trabalhadas, limitando-se as entidades a copiar os serviços já oferecidos pelos demais bancos, uma vez que não existe proteção sobre a marca dos serviços prestados. Entende-se ser uma prática conservadora, característica do sistema financeiro nacional.

O gráfico em forma de radar, elaborado com base nas averiguações referentes às dimensões estudadas, apontou as deficiências de gestão da inovação por meio do descolamento da situação obtida por intermédio da auditoria com a situação considerada ideal. Mostrou igualmente que as dimensões com menores conceitos médios apresentam-se uniformes, de onde se vê que a empresa atribui a mesma relevância proporcional às dimensões que o modelo ideal, embora com menor grau de desenvolvimento. Qualifica-se a gestão da inovação do Banese, portanto, de modo geral, como satisfatória em relação ao modelo utilizado, já que os valores obtidos para as dimensões aproximamse mais do maior limite do radar, tendendo à situação ideal.

No que diz respeito às limitações desta pesquisa, considera-se o fato de o estudo ter sido realizado em apenas uma instituição bancária; assim sendo, sugere-se, para futuros estudos, a replicação em várias instituições bancárias e a comparação dos resultados obtidos com os encontrados no presente artigo. 


\begin{abstract}
Innovation management has taken on an important role in current business environment as a means of making profit, achieving process efficiency and structural flexibility, which are important for the competitiveness of the organization and consolidation in the market aspects. The intent of this theoretical and empirical study is to analyze the process of innovation management in banks, taking the Bank of Sergipe state (BANESE) as object, and using as an analysis tool an internal audit of innovation, according to the model proposed by Tidd, Bessant and Pavitt (2008), which is based on five dimensions: strategy, processes, innovative organization, relationships and learning, with the result presented in the form of radar chart. After applying questionnaires with the managers of Banese departments involved with innovation, the responses were analyzed and graded according to the proposed model. Then, weaknesses were identified and suggestions for improvement were made. The result of this research pointed to the lack dissemination of the culture of innovation focusing on customer and competitiveness.The research also verified the need for convergence of innovation actions and the company's strategic plan as well as the need for measuring the results of innovative projects which should be prioritized, with interaction between departmental units and external agents fostering innovation.
\end{abstract}

Keywords: Innovation. Management. Audit.

\title{
REFERÊNCIAS
}

BERNARDES, R. Inovação em serviços intensivos em conhecimento. São Paulo: Saraiva, 2007.

BERNSTEIN, R. R. Problem generation and innovation. In: SHAVININA, L.V. (Ed.). International Handbook of Innovation. Oxford: Elsevier, 2003. p. 170-179.

CASTRO, M. T. B. Inovação predatória no ordenamento jurídico brasileiro. 124f. Dissertação (Mestrado em Direito) - Universidade Federal do Rio de Janeiro, Rio de Janeiro, 2008.

CERNEV, A. K.; JAYO, M.; DINIZ, E. H. Emergência da quinta onda de inovação bancária. Proceedings of the Fifteenth Americas Conference on Information Systems, v. 6, n. 9, San Francisco, Califórnia, p. 6-9, 2009.

CHESBROUGH, H. Business model innovation: opportunities and barriers. Long Range Planning, v. 43, p. 354-363, 2010.

DEMO, P. Metodologia do conhecimento científico. São Paulo: Atlas, 2000.

DRUCKER, P. F. Inovação e espírito empreendedor. 3. ed. Rio de Janeiro: BPAN, 1985.

IBGE. Instituto Brasileiro de Geografia e Estatística. [2008]. Disponível em: <http://www.ibge. gov. br.>. Acesso em: 11 jul. 2013.

KATZ, R. Managing Technological Innovation in Business Organizations. In: SHAVININA, L.V. (Ed.). International Handbook of Innovation. Oxford: Elsevier, 2003. p. 775-788.

LIMA, A. F. et al. Risco e inovação de produtos: um estudo de empresas manufatureiras brasileiras. In: Congresso USP de Controladoria e Contabilidade, 7., 2007, São Paulo. Anais... São Paulo: USP. p. 215-236.

LUECKE, R. Essentials of Managing Creativity and Innovation. Cambridge: HBS, 2002.

MACEDO, S. L. J. Migração de competências de inovação em produto para inovação em serviço: um desafio para empresas de alta intensidade tecnológica. 129f. Dissertação (Mestrado Profissional em Administração) - Fundação Getúlio Vargas, São Paulo, 2008. 
OECD - Organization for Economic Co-Operation and Development. Promoting innovation in services. Paris: OECD, 2005.

PIRES, M. R.; MARCONDES, R. C. Conhecimento, inovação competência em organizações financeiras: uma análise sob o ponto de vista de gestores de bancos. Revista de Administração Contemporânea (RAC), Rio de Janeiro, Edição Especial, v. 4, p. 61-78, 2004.

RICHARDSON, R. Pesquisa social: métodos e técnicas. 3. ed. São Paulo: Atlas, 2008.

SAUNDERS, M. N. K.; LEWIS, P.; THORNHILL, A. Research Methods for Business Students. 6. ed. Pearson: Harlow, 2012.

SCHUMPETER, J. A Teoria do Desenvolvimento Econômico: uma investigação sobre lucros, capital, crédito, juro e o ciclo Econômico. São Paulo: Abril, 1982.

STAL, E. Inovação tecnológica, sistemas nacionais de inovação e estímulos governamentais. In: MOREIRA, D. A.; QUEIROZ, A. C. S. (Coord.) Inovação organizacional e tecnológica. São Paulo: Thomson Learning, 2007. p. 28-67.

STERNBERG, R. J.; PRETZ, J. E.; KAUFMAN, J. C. Types of Innovation. In: SHAVININA, L.V. (Ed.). International Handbook of Innovation. Oxford: Elsevier, 2003. p.158-169.

SUNDBO, J.; GALLOUJ, F. Innovation in services. Oslo: Noruega, 1998.

TETHER, B. S. What is innovation? Approaches to Distinguishing New Products and Processes from Existing Products and Processes.[2003]. Disponível em: <http://www.cric.ac.uk/cric/pdfs/wp12. pdf $>$. Acesso em: 16 nov. 2014.

TIDD, J. Innovationmanagemente in context: environment, organizationand performance. International Journal of Management Reviews, Oxford, v. 3, n. 3, p. 169-183, 2001.

TIDD, J; BESSANT, J.; PAVITT, K. Gestão da Inovação. 3. ed. Porto Alegre: Bookman, 2008.

VILHENA, J. B. A diferenciação dos serviços bancários. [2011]. Disponível em: <http://www. institutomvc.com.br/costacurta/artjbv08_diferenciacao_servicos_bancarios.htm>. Acesso em: 16 jun. 2013.

WEISBERG, R.W. Case studies of innovation: ordinary thinking, extraordinary outcomes. In: SHAVININA, L.V. (Ed.). International Handbook of Innovation. Oxford: Elsevier, 2003. p. 204-247.

YIN, R. K. Estudo de Caso: planejamento e métodos. 4. ed. São Paulo: Bookman, 2010. 